\title{
GEOPROCESSAMENTO APLICADO NA AVALIAÇÃO MORFOMÉTRICA DA MICROBACIA DO RIBERIÃO TABULETA - PIQUETE (SP)
}

\author{
Sérgio Campos ${ }^{1}$ \\ Teresa Cristina Tarlé Pissarra \\ Elen Fittipaldi Brasílio Carrega
}

RESUMO: A análise morfométrica de uma microbacia é uma importante ferramenta de diagnóstico da susceptibilidade à degradação ambiental, pois os resultados nortearão o planejamento, o manejo e a implementação de medidas mitigadoras para conservação dos recursos hídricos. O presente trabalho teve como objetivo a caracterização morfométrica da microbacia do Ribeirão Tabuleta - Piquete (SP) através do Sistema de Informações Geográficas Arcview e da Carta Planialtimétrica de Lorena - SP e Delfim Moreira MG, editadas pelo IBGE (1970), em escala 1:50000. As variáveis avaliadas foram as dimensionais, da composição da rede de Drenagem e do padrão de drenagem. As bases cartográficas utilizadas foram a carta planialtimétrica de Lorena - SP e Delfim Moreira - MG, editadas pelo IBGE (1970), em escala 1:50000, para a hierarquização da rede de drenagem e a análise morfométrica. Os resultados permitiram concluir que a microbacia apresenta altos riscos de susceptibilidade a erosão e degradação ambiental, sendo fundamental a manutenção da cobertura vegetal e as zonas ripárias para conservação dos serviços ambientais. O fator de forma e a densidade de drenagem alta permitiram inferir que o substrato tem permeabilidade baixa com menor infiltração e maior escoamento da água. A alta declividade das encostas (montanhoso) indica se não for conservada pode haver alteração na regulação do sistema hidrológico e consequentemente na produção de água. O Sistema de Informações Geográficas ArcGis 9.3 foi excelente na digitalização e análise dos dados.

Palavras-chave: variáveis morfométricas, geoprocessamento, microbacia.

\footnotetext{
1 Prof. Adjunto, Departamento de Engenharia Rural, Faculdade de Ciências Agronômicas/UNESP. seca@fca.unesp.br
}

VIII Fórum Ambiental da Alta Paulista, v. 8, n.2, 2012, p. 422-436. 


\section{INTRODUÇÃO}

O monitoramento contínuo dos recursos hídricos é um instrumento essencial para melhor avaliar os fenômenos hidrológicos críticos, envolvendo tanto as secas quanto inundações. Com a adequada avaliação dos recursos hídricos utilizando o monitoramento dos dados relativos a uma microbacia por exemplo, pode-se propor uma adequação da ocupação do solo em relação ao seu potencial e de suas limitações, tornando possível um manejo racional e equilibrado com a natureza, conquistando assim a sustentabilidade. Esta microbacia faz parte do manancial da Bacia do Rio Paraíba do Sul, na qual é uma das mais importantes por serem as principais fontes de abastecimento e afastadoras das águas poluídas no município de Piquete (Silva, 2004).

A implantação de uma política agrícola adequada e séria necessita de embasamento técnico e científico, com informações confiáveis e atualizadas sobre o grau de uso e utilização das terras e sobremaneira com o intuito de racionalizar e viabilizar o planejamento agrícola de determinada região, face à grande extensão territorial do país e à diversidade de uso, relevo, clima e tipos de solos encontrados nas diversas regiões.

A possibilidade de obtenção de dados georreferenciados, obtidos por sensoriamento remoto e a sobreposição de mapas (substituindo o processo convencional na elaboração de mapas), viabiliza sua confecção com certa rapidez, permitindo um exame amplo do conjunto de variáveis que são usualmente consideradas nos planejamentos de manejo do solo.

No planejamento de recursos naturais, têm sido utilizadas ferramentas digitais para aquisição, análise e divulgação de informações espaciais, como os Sistemas de Informações Geográfica (SIG).

O sistema de informação geográfica (SIG) utiliza uma base de dados computadorizada que contém informação espacial (aspectos no meio natural como relevo, solo, clima, vegetação, hidrologia, etc., e os aspectos sociais, econômicos e políticos, que permitem uma divisão temática em subsistemas que integram um SIG, sendo esses componentes os atributos), sobre a qual atua uma série de operadores espaciais 
(conjunto de operações algébricas, booleanas e geométricas, utilizadas no cruzamento de dados pelo SIG). Verifica-se que a principal característica dos SIGs é focalizar o relacionamento de determinado fenômeno da realidade com sua localização espacial. Podem-se estudar outros aspectos mais complexos, como a vizinhança e contigüidade envolvendo áreas extensas (TEIXEIRA et al., 1992).

A morfometria é uma ferramenta fundamental no diagnóstico de susceptibilidade á degradação ambiental, delimitação da zona ripária, planejamento e manejo de microbacias (Moreira e Rodrigues, 2010), pois a sua caracterização permite descrever a formação geomorfológica da paisagem em sua variação topográfica (Christofoletti, 1980), bem como possui um papel significativo no condicionamento de respostas ligadas à erosão hídrica, gerado após eventos pluviométricos relevantes (Arraes et al., 2010).

Nesse sentido, é possível avaliar o comprimento da rede de drenagem e suas relações com a área de microbacias e associar esses valores a problemas de enchentes e erosões ao longo do curso d'água (Torres et al., 2007).

O presente trabalho teve como objetivo a caracterização morfométrica da microbacia do Ribeirão Tabuleta - Piquete (SP) em ambiente do Sistema de Informações Geográficas Arcview, visando o planejamento e o manejo integrado dos recursos hídricos da área.

\section{MATERIAL E MÉTODOS}

\subsection{Aspectos gerais da área}

A microbacia do Ribeirão Tabuleta, uma das principais abastecedoras e afastadoras de águas usadas na área urbana do Município de Piquete, SP, com uma de 835ha, encontra-se localizada entre as coordenadas UTM, longitudes 473110m a 478670m W e 7500120 a 7500235 S, na porção noroeste do médio vale do Rio Paraíba do Sul. Possui cerca de $40 \%$ de sua área dentro da APA da Mantiqueira, a qual foi criada pelo decreto 91.304 de 03/06/1985, e possui 23\% de área com vegetação natural composta de remanescentes da Floresta Atlântica, concentrados principalmente a noroeste do município, na Serra da Mantiqueira (Kurkdjian et al., 1992), estando também 


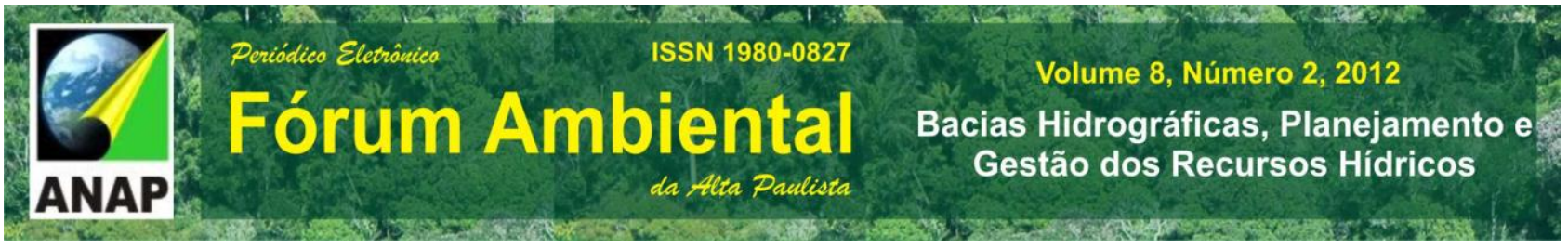

situado em Área de Proteção e Recuperação de Mananciais do Rio Paraíba do Sul; local estratégico em função dos recursos hídricos, com áreas propensas para servir de corredor ecológico da região da Mantiqueira.

A área desta microbacia está caracterizada pelo relevo montanhoso, com terrenos bastantes declivosos e a ocorrência de processos erosivos em certos locais. As características do relevo e o tipo de solo dessa área fazem com que estes ambientes, associados aos índices pluviométricos acentuados e declives fortes, tornem-se vulneráveis. Estas características, somadas à utilização inadequada de certos trechos com fins de reflorestamento de espécies exóticas e a ação antrópica, ocasionam um desequilíbrio rápido, comprometendo o equilíbrio ecológico deste ambiente.

A base cartográfica para medição dos parâmetros morfométricos foram as cartas planialtimétricas do Município de Lorena-SP (SF 23-Y-B-VI-2) e Delfim Moreira-MG (SF 23-Y-B-VI-1), projeção Universal Transversa de Mercator (UTM), editadas pelo IBGE. (1970), com curvas de nível eqüidistantes de 20 metros e fotografias aéreas verticais pancromáticas, em escala nominal aproximada de 1:25000, da Base Aerofotogrametia S/A (1962).

As medições das distâncias retas, distâncias curvas, para os segmentos de rio e o perímetro das microbacias foram efetuadas utilizando o software Arcview (Esri), no qual foi armazenado o banco de dados.

\section{2 Caracterização da ordem}

A hierarquização da microbacia do Córrego Tabuleta foi obtida segundo o sistema de Strahler (1957), que modificou o sistema de classificação de rios de Horton (1945), introduzindo o conceito de segmento de rio, onde a junção de dois segmentos de mesma ordem origina um segmento de ordem superior e a união de dois canais de ordens diferentes permanecerá o de ordem maior.

\subsection{Variáveis dimensionais}

A análise de variáveis dimensionais da microbacia do Córrego Tabuleta, realizadas segundo procedimentos e métodos de geoprocessamento no software ArcGis 9.3, a partir do comando measure na guia tools (perímetros e comprimentos), foram as seguintes: 


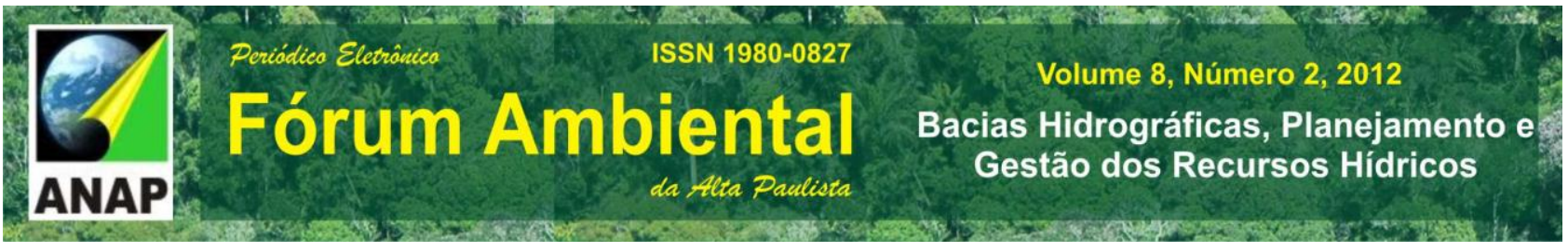

Área $(\mathbf{A})$ : compreende a extensão circunscrita pela linha do divisor de água que delimita a microbacia, este parâmetro representa toda a área drenada pelo conjunto do sistema fluvial, projetado no plano horizontal, é expressa em quilômetros quadrados (Horton, 1945); Perímetro (P): compreende a linha limítrofe da microbacia que é representada pela linha do divisor topográfico que circunda a microbacia, expresso em quilômetros (Smith, 1950); Maior Comprimento (C): representa a medida do comprimento da linha que une a foz até o ponto extremo da microbacia, localizado sobre a linha do divisor topográfico, que segue a direção do vale principal, sendo expressa em quilômetros (Schum, 1956); Maior Largura (L): é a maior dimensão linear que a microbacia apresenta num eixo transversal ao vale por ela formado, sendo medida transversalmente ao maior comprimento, expressa em quilômetros (Strahler, 1958) e Comprimento Total da Rede (Cr): corresponde ao comprimento do conjunto de todos os segmentos de rios que formam a rede de drenagem da microbacia hidrográfica, sendo mensurada em quilômetros (Horton,1945).

\subsection{Variáveis da composição da rede de drenagem}

A composição da rede de drenagem refere-se ao número e comprimento de rios nas diferentes ordens de ramificação de uma bacia (Horton, 1945) permitiu determinar os números de segmentos de rios $(\mathrm{Nw})$ e o número total de segmentos de rios (Nt) da microbacia. A razão de ramificação ou de bifurcação $(R b)$ correspondente à média aritmética da relação entre o número de segmentos de rios de uma dada ordem e o da ordem imediatamente seguinte (Horton, 1945), conforme a fórmula: $R b=\left[\left(N_{w} 1 / N w 2\right)+\right.$ $(\mathrm{Nw} 2 / \mathrm{Nw} 3)+(\mathrm{Nw} 3 / \mathrm{Nw} 4)] / 3$. O comprimento total de segmentos de rios (Lt) foi determinado através dos comandos do aplicativo ArcGis 9.3. A razão de comprimento total (Rlw) correspondente à média aritmética da relação entre as somas dos comprimentos de segmentos de rios de uma dada ordem e o da ordem superior (Strahler, 1957), correspondente à fórmula: $R l w=[(L w 1 / L w 2)+(L w 2 / L w 3)+(L w 3 / L w 4)] / 3 . O$ comprimento médio de segmentos de rios (Lmw) foi obtido a partir da relação entre a soma dos comprimentos de rios de cada ordem (Lw) pelo número de segmentos de rios da referida ordem $(\mathrm{Nw})$. A razão de comprimento médio $(\mathrm{Rl})$ correspondente à média aritmética da relação entre o comprimento médio de segmentos de rios de uma dada 
ordem e o da ordem imediatamente inferior (HORTON, 1945), dado pela fórmula: RI = $[(L m w 4 / L m w 3)+(L m w 3 / L m w 2)+(L m w 2 / L m w 1)] / 3$.

\subsection{Variáveis do padrão da rede de drenagem}

A rede de drenagem foi decalcada das fotografias aéreas conforme sugestão de Lueder (1959) e Strahler (1957), considerando-se os cursos d'água permanentes ou temporários, estes quando estabilizados. Para a avaliação da morfometria das redes fluviais foram utilizados os seguintes parâmetros: Número de Segmentos de Rios (N): 0 número de segmentos de rios em cada ordem e o número total de segmentos de rios da microbacia, sendo identificados, respectivamente, por Nw1, Nw2 e Nt, de acordo com Horton (1945), Strahler (1957) e França (1968); Comprimento Total de Segmentos de Rios em cada Ordem (Ctw): representa o comprimento total dos segmentos de rios em cada ordem sendo identificados respectivamente por Ctw1 e Ctw2, sendo expressos em quilômetro (km), França (1968); Comprimento Médio de Rios em cada Ordem (Cmw): é a relação entre o comprimento total de segmentos de rios e número de segmentos de rios determinados para cada ordem, sendo identificada por Cmw1 e Cmw2. Este índice é obtido pela expressão $\mathrm{Cm}=\mathrm{Cr} / \mathrm{Nt}$, França (1968); Razão de Ramificação ou Bifurcação (Rb): expressa a relação entre o número de segmentos de rios de uma determinada ordem e o número de segmentos da ordem imediatamente superior, Horton (1945) e Strahler (1957), sendo determinada pela expressão $\mathrm{Rb}=\mathrm{Nw}^{1} / \mathrm{Nw}^{2}$; Razão de Comprimentos Totais (RIw): é a relação entre a soma dos comprimentos de segmentos de rios de uma dada ordem e soma dos segmentos da ordem imediatamente superior, Strahler (1957), sendo obtida pela expressão Rlw = Ctw1 / Ctw2; Razão de Comprimentos Médios (RIm): é a relação entre o comprimento médio de segmentos de rios de uma dada ordem e o comprimento médio dos segmentos da ordem imediatamente inferior, de acordo com Horton (1945), sendo calculada pela expressão: $\mathrm{Rlm}=\mathrm{Cmw}^{2} / \mathrm{Cmw}^{1} \mathrm{e}$ Relação entre a Razão de Comprimentos Médios e a Razão de Ramificação (Rlb): expressa a relação entre a razão de comprimentos médio $(\mathrm{R} \mid \mathrm{m})$ e a razão de ramificação $(\mathrm{Rb})$, Strahler (1958), sendo calculada pela expressão: $\mathrm{Rlb}=\mathrm{R} / \mathrm{m} / \mathrm{Rb}$. 


\subsection{Variáveis do padrão de relevo}

As variáveis do padrão de relevo estudadas foram a declividade média (D), calculada pela equação: $\mathrm{D} \%=(\square \mathrm{Cn} \times \square \mathrm{H}) / \mathrm{A}$, ou seja é a relação entre a somatória do comprimento das curvas de nível multiplicada pela eqüidistância entre as cotas ( $\square \mathrm{H})$ e a área $(A)$ da microbacia. A altitude média da microbacia $(\mathrm{Hm})$ foi obtida através da média aritmética entre os valores de maior altitude (AM) observada na cabeceira e a menor altitude $(\mathrm{Am})$ na foz ou desembocadura em $(\mathrm{m})$. A amplitude altimétrica $(\mathrm{H})$ é a diferença entre a maior e a menor altitude da microbacia, expressa em metros (Sthraler, 1957). O fator de forma (Ff), segundo Horton (1945) foi obtido segundo a equação: $F f=A / C^{2}$, onde A é a área em $\mathrm{km}^{2}$ e $\mathrm{C}$ o comprimento em $\mathrm{km}$. O coeficiente de rugosidade (RF) foi calculado através da fórmula: $R F=D d \times D$, onde $D d$ é a densidade de drenagem e $D$ a declividade média em porcentagem, conforme Rocha (1999). A Razão de Relevo (Rr): é a relação entre a amplitude altimétrica e o maior comprimento da microbacia, sendo calculada pela expressão $\mathrm{Rr}=\mathrm{H}$ / C (Schumm,1956); Razão de Relevo Relativo (Rrl): é a relação entre a amplitude altimétrica e o perímetro da microbacia, sendo calculada pela expressão $\mathrm{Rrl}=\mathrm{H} / \mathrm{P}$; Índice de Rugosidade (HD): é obtido pelo produto da expressão amplitude altimétrica $(H)$ x densidade de drenagem (Dd), Strahler (1958) e Declividade Média da Encosta (DME): é obtida em função do índice de rugosidade por meio da expressão $\mathrm{DME}=\mathrm{tg}$, sendo $\mathrm{tg}=2 \mathrm{HD}$. O valor em \% é obtido pela transformação do valor de DME em graus para declive em m/100m., Strahler (1958). O índice de circularidade é dado pela relação entre a área total da mcirobacia $\left(\mathrm{Km}^{2}\right)$ e a área do circula (Ac) de perímetro igual ao da área total da microbacia (Muller, 1953; Schumm, 1956 e Christofoletti, 1980); ou seja é dado pela equação: Ic = 12,57 (A/Ac $\left.{ }^{2}\right)$.

\section{RESULTADOS E DISCUSSÃO}

A morfometria da microbacia do Córrego Tabuleta (Figura 1), classificada como de $3^{\mathrm{a}}$ ordem de ramificação, segundo o sistema de Strahler (1957), que modificou o sistema de classificação de rios de Horton (1945), é reflexo das condições do meio físico em que 


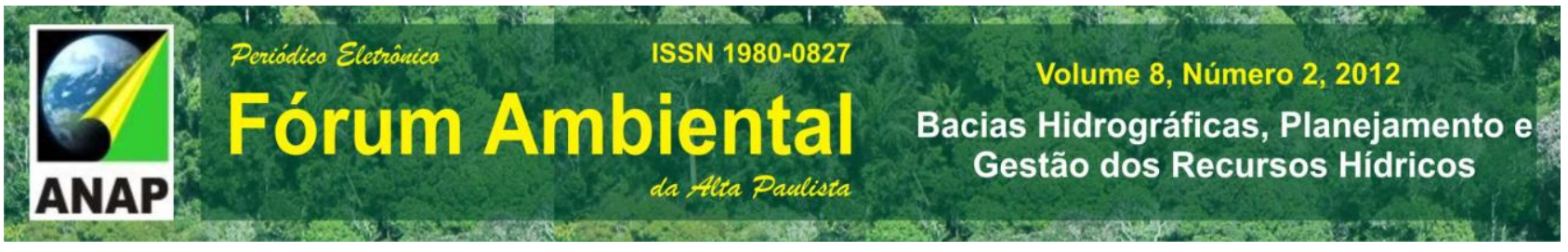

estão relacionadas com a litologia, a estrutura geológica e o material superficial (Silva, 2003). Esta microbacia se caracteriza por possuir canais mais extensos e ter uma forma triangular, sendo que num evento de precipitação forte a água oriunda de vários pontos tende a chegar de maneira simultânea ao canal principal, podendo produzir uma enchente maior, porém de curta duração. As suas características qualitativas em relação à drenagem são dentrítico, com grau de integração alto, densidade baixa, e orientada (Vieira, 1991).

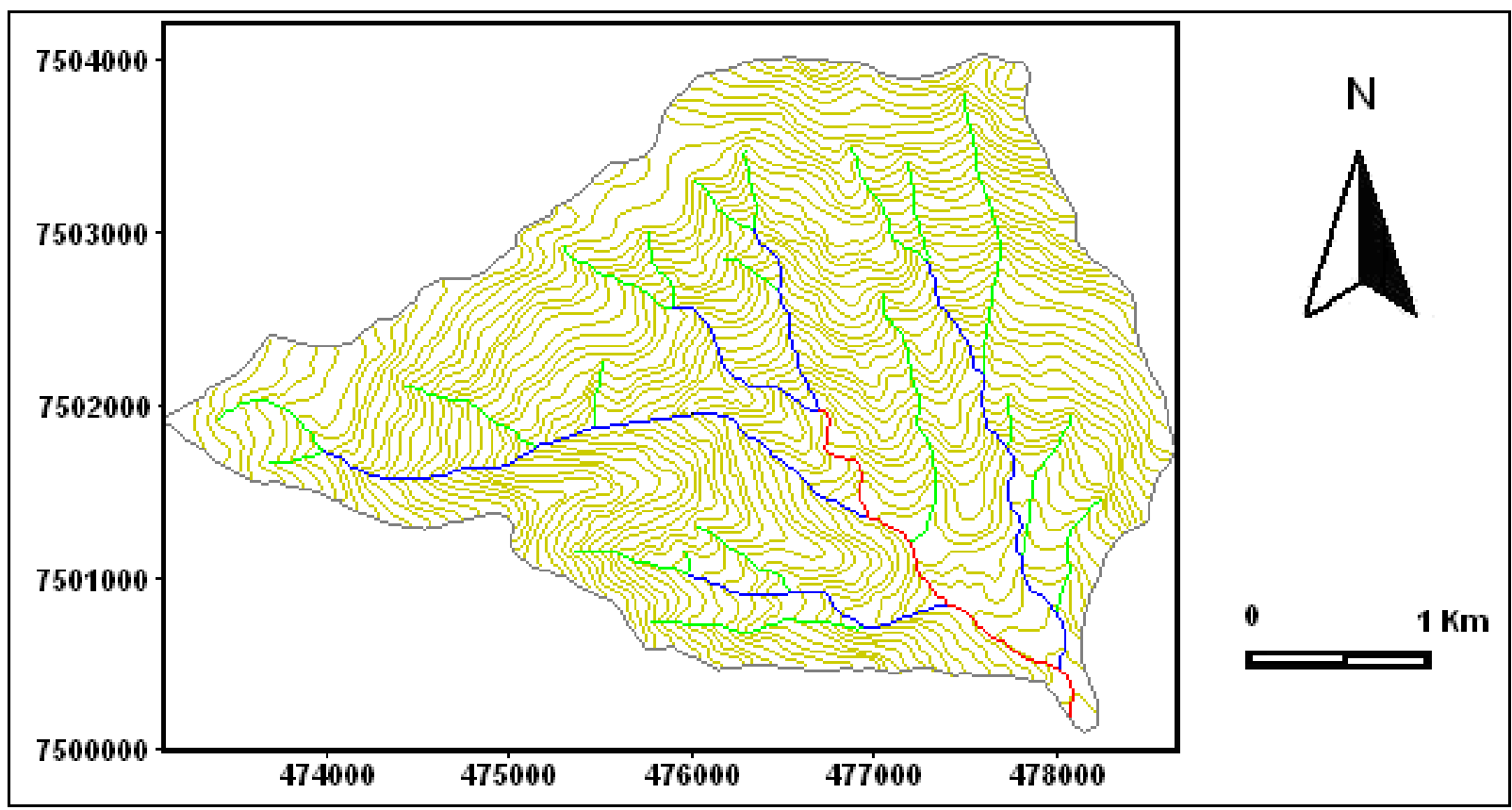

Figura 1. Hierarquização da microbacia do Córrego Tabuleta - Piquete (SP), conforme Strahler (1952).

A análise das variáveis dimensionais (Quadro 1) permitiu constatar que a área da microbacia da Córrego Tabuleta foi calculada em 7,205 km². Esta variável é uma das mais importantes, visto que quase todas as outras características estão relacionadas a ela (Moreira e Rodrigues, 2010) e porque esta aumenta exponencialmente com o aumento da ordem de ramificação dos rios (Schumm, 1956) e variam em conformidade com a relação infiltração/deflúvio.

\section{Quadro 1. Parâmetros Dimensionais da Microbacia do Ribeirão Tabuleta}

\begin{tabular}{|l|l|l|l|l|}
\hline Área $(\mathrm{A})$ & Perímetro & Maior & Maior Largura & Compr. Total da \\
\hline
\end{tabular}

VIII Fórum Ambiental da Alta Paulista, v. 8, n.2, 2012, p. 422-436. 


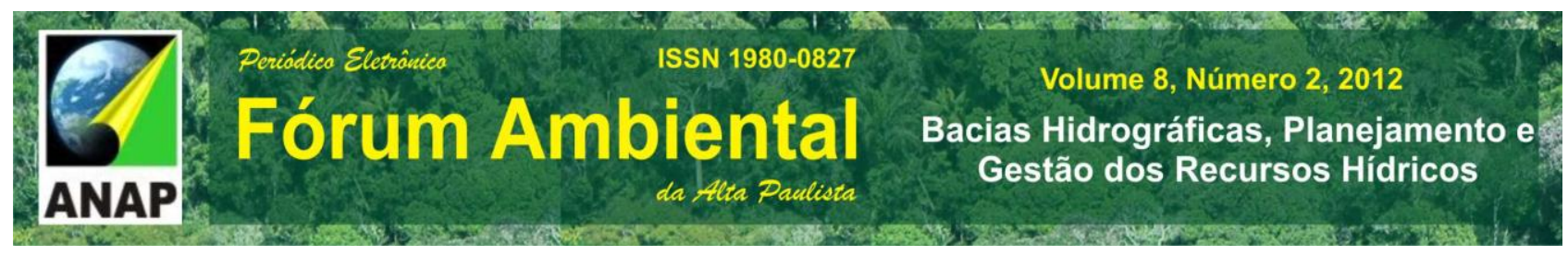

\begin{tabular}{|c|c|c|c|c|}
\hline & $(\mathrm{P})$ & $\begin{array}{c}\text { Comprimento } \\
(\mathrm{C})\end{array}$ & $(\mathrm{L})$ & Rede $(\mathrm{Cr})$ \\
\hline $8,34 \mathrm{Km}^{2}$ & $13,13 \mathrm{Km}$ & $3,50 \mathrm{Km}$ & $3,26 \mathrm{Km}$ & $21,74 \mathrm{Km}$ \\
\hline
\end{tabular}

As variáveis dimensionais são estudadas por muitos pesquisadores brasileiros, pois elas permitem a diferenciação das unidades de solos, bem como servem para agrupar microbacias de uma mesma unidade de solo (Cardoso e Piedade (1989); Manzoli Júnior (1990) e Amaral (1991).

A análise das variáveis da composição da rede de drenagem (Quadro 2) permite analisar a variação destes ao longo dos anos, pois essa variação pode estar associada a um controle efetivo de erosão ou também às vezes em virtude do desaparecimento ou aparecimento de um novo segmento de rio, que sugerem modificações locais quando se analisa amostras homólogas de diferentes anos Campos, 1993).

\section{Quadro 2. Composição da Rede de Drenagem da Microbacia do Ribeirão Tabuleta}

\begin{tabular}{|c|c|c|c|c|c|c|c|}
\hline CRD & $\mathbf{N}$ & CTW & Cmw & Rb & Rlw & Rlm & Rlb \\
\hline Primário & 20 & $11,55 \mathrm{Km}$ & $577,50 \mathrm{Km}$ & 4 & $1,43 \mathrm{Km}$ & $2,80 \mathrm{Km}$ & 0,70 \\
\hline Secundário & 5 & $8,07 \mathrm{Km}$ & $1614,09 \mathrm{Km}$ & 5 & $3,82 \mathrm{Km}$ & ---- & ---- \\
\hline Terciário & 1 & $2,12 \mathrm{Km}$ & ---- & ---- & ---- & ---- & ---- \\
\hline
\end{tabular}

Obs: Composição da Rede de Drenagem (CRD); Número de Segmentos de Rios (N); Comprimento Total de Segmentos de Rios em cada Ordem (CTW); Comprimento Médio de Rios em cada Ordem (Cmw); Razão de Ramificação ou Bifurcação (Rb); Razão de Comprimentos Totais (Rlw); Razão de Comprimentos Médios (RIm) e Razão de Comprimentos Médios e a Razão de Ramificação (Rib)

A maturidade de uma rede de drenagem ocorre quando o desenvolvimento e a expansão dos cursos d'água atingem o seu tamanho ótimo, alcançando assim o equilíbrio quando as condições ambientais permitem (Machado, 1983), podendo ser verificado através de estudo mais detalhado dos segmentos de rios e da rede de drenagem ao longo dos anos.

As microbacias, normalmente se apresentam no formato de pêra, mas podem ter outras formas que depende da interação clima, geologia entre outras. A superfície da microbacia é sempre côncava, a qual determina a direção do fluxo de água, LIMA (1986).

A densidade de drenagem para Christofoletti (1974) é um parâmetro físico fundamental na análise comparativa da susceptibilidade entre microbacias, pois relaciona 


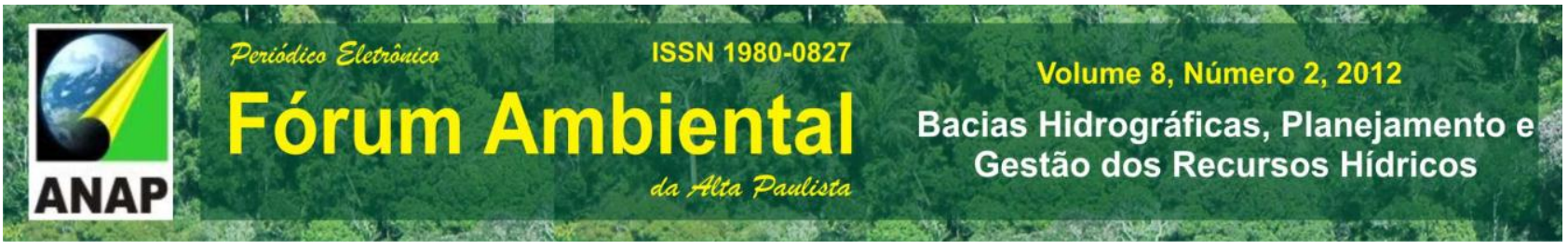

o comprimento total da rede de drenagem (CR) e a área $(A)$, e quanto maior for o valor do comprimento da rede de drenagem $(\mathrm{Cr})$ maior será o perigo de erosão. A densidade de drenagem de $2,61 \mathrm{~km} / \mathrm{km}^{2}$ para a microbacia do Córrego Tabuleta foi classificada como alta (França, 1968) que classifica como alta quando os valores maiores que 2,5, o que permite inferir que o substrato tem permeabilidade baixa com menor infiltração e maior escoamento superficial da água. Para Ray (1963), a densidade de drenagem em um dado ambiente climático esta relacionada principalmente com a resistência à erosão dos materiais presentes, aumentando à medida que diminui a resistência à erosão. Nesse sentido, as matas são fundamentais no controle da erosão e de enchentes e, quando situadas em locais preservados adequadamente são fundamentais na recarga do lençol freático.

A razão de bifurcação (Rlb) para Chorley (1971) exprime a velocidade de escoamento da água numa microbacia, indicando que quanto maior o valor do índice, mais rápido será o escoamento da água, pois o formato alongado das microbacias é devido à existência de maior controle estrutural. Assim, o valor de 2,93 para a razão de bifurcação na microbacia foi considerada média (Horton, 1945).

O comprimento de rios ( $\mathrm{Cr}$ ) permitiu constatar que a microbacia apresenta uma rede de drenagem de aproximadamente $15,7 \mathrm{~km}$, denotada através dos seus comprimentos totais de $1^{\mathrm{a}}$ e $2^{\mathrm{a}}$ e total.

A razão de textura $(\mathrm{T})$ de 1,98 indica um relevo com poucos recortes, com uma textura topográfica grosseira menor que 2,5. A freqüência de rios deste ambiente hidrográfico foi considerada baixa $(\mathrm{Fr}=3,12)$ e a declividade encontrada de 53,2\% permitiu classificá-la como muito alta e o relevo como "Montanhoso" de acordo com as classes de declividades e tipos de relevo do Sistema Brasileiro de Classificação de Solos da EMBRAPA (1999). A alta declividade tem relação direta importante com os processos erosivos devido a maior velocidade da água do escoamento superficial e menor infiltração da água das chuvas, resultando em alteração na regulação do sistema hidrológico e conseqüentemente na produção de água da microbacia (Moreira e Rodrigues, 2010).

\section{Quadro 3. Variáveis do Padrão de Drenagem da Microbacia do Ribeirão Tabuleta}

\begin{tabular}{|c|c|c|c|c|}
\hline \multicolumn{5}{|c|}{ Variáveis do Padrão de Drenagem em Km } \\
\hline $\mathrm{Dd}$ & $\mathrm{F}$ & $\mathrm{T}$ & $\mathrm{Eps}$ & $\mathrm{Cm}$ \\
\hline
\end{tabular}

VIII Fórum Ambiental da Alta Paulista, v. 8, n.2, 2012, p. 422-436. 


\section{2,61}

3,12

1,98

1,30

383,72

OBS : Densidade de Drenagem (Dd); Freqüência de Rios (F); Razão de Textura (T); Extensão de Percurso Superficial (Eps) e Coeficiente de Manutenção (Cm).

O padrão de drenagem é o resultado do trabalho das águas que atingem, penetram e se escoam pela superfície do solo (Silva, 2003).

A análise das variáveis do relevo (Quadro 4) permitiram verificar que a amplitude altimétrica $(1025 \mathrm{~m})$ é um diferencial entre as cotas máxima e mínima, sendo a maior altitude (AM) de 805 metros a montante e menor altitude (Am) de 465 metros a jusante, resultando em $340 \mathrm{~m}$ de amplitude altimétrica.

Quadro 4. Variáveis do Relevo da Microbacia do Ribeirão Tabuleta

\begin{tabular}{|c|c|c|c|c|c|c|}
\hline \multicolumn{7}{|c|}{ Variáveis do Relevo } \\
\hline $\mathbf{H}$ & $\mathbf{R r}$ & $\mathbf{R r l}$ & HD & DME & Ff & IC \\
\hline $1025,00 \mathrm{~m}$ & 215,65 & 78,03 & 2671,22 & 53,42 & 0,68 & 0,61 \\
\hline
\end{tabular}

Obs: Amplitude Altimétrica (H); Razão de Relevo (Rr); Razão de Relevo Relativo (Rrl); Índice de Rugosidade (HD), Declividade Média da Encosta (DME) e Fator de forma (Ff).

As microbacias de formatos circulares, ovais ou quadradas apresentam um maior perigo de enchentes, devido terem maiores possibilidades de chuvas intensas ocorrerem simultaneamente em toda a sua extensão superficial, concentrando grande volume de água no tributário principal, porém sabe-se que o perigo de enchentes depende também da permeabilidade do solo e da cobertura vegetal.

O valor de 0,68 para o índice de forma da microbacia é considerado alto, indicando que a microbacia apresenta maior susceptibilidade à degradação, pois quanto mais próximo de 1 for o fator de forma, mais próxima do formato circular será a microbacia e, consequentemente menor será o tempo de concentração (Tc) das águas das chuvas, pois as enxurradas provocam inundações, que possivelmente causarão erosões do solo e degradação da zona ripária da microbacia.

O índice de circularidade de 0,61 mostra que quanto mais próximo de 1 , mais a microbacia estará próxima do formato circular e quanto maior for este valor, maior será o perigo de enchentes. 


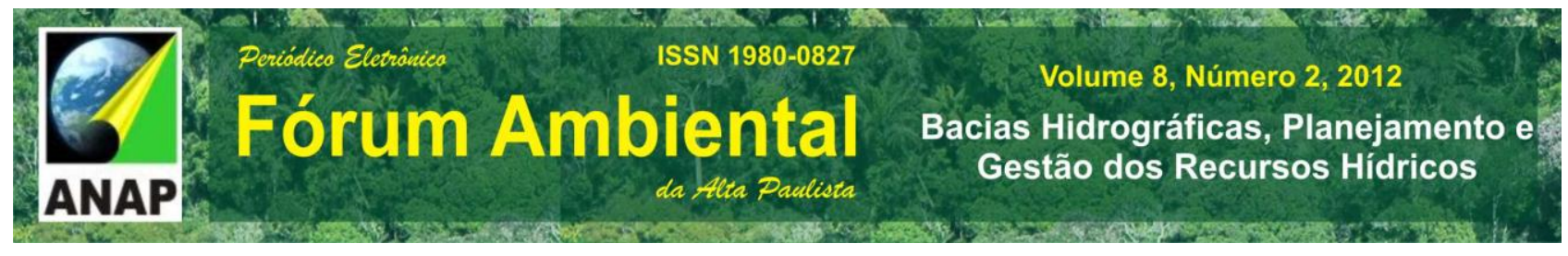

Os serviços ambientais da floresta na microbacia hidrográfica, tais como: produção de água, manutenção da biodiversidade, seqüestro de carbono e beleza cênica da paisagem, são de fundamental importância na preservação da biosfera. A morfometria é uma ferramenta de grande importância como diagnóstico de suscetibilidade a degradação ambiental, delimitação da zona ripária, planejamento e manejo da microbacia.

\section{CONCLUSÕES}

Os resultados da morfometria da microbacia do Córrego Tabuleta - Piquete (SP) permitiram concluir que as variáveis morfométricas servirão para futuros planejamentos e gestões ambientais regionais. A microbacia apresenta altos riscos de susceptibilidade à erosão e degradação ambiental, sendo fundamental a manutenção da cobertura vegetal e as zonas ripárias para conservação dos serviços ambientais. O fator de forma $(0,68)$ e a densidade de drenagem de $2,61 \mathrm{~km} . \mathrm{km}^{2}$, classificado como alto, permitem inferir que 0 substrato tem permeabilidade baixa com menor infiltração e maior escoamento da água. $A$ alta declividade das encostas $(53,42 \%)$ de acordo com as classes de declividade foi classificada como montanhoso, indicando que se não for conservada pode haver alteração na regulação do sistema hidrológico e consequentemente na produção de água. O sistema de Informações Geográficas ArcGis 9.3 foi excelente para a vetorização e análise dos dados.

\section{REFERÊNCIAS}

AMARAL, C. Fotointerpretação de características de bacias hidrográficas de terceira ordem na diferenciação de unidades de solo. Botucatu: UNESP, 1991. 104p. Tese (Doutorado em Energia na Agricultura) - Faculdade de Ciências Agronômicas, Universidade Estadual Paulista, 1991.

ARRAES, c.I. ET AL. Morfometria dos compartimentos hidrológicos do Município de Jaboticabal, SP. Unopar., Londrina, v.9, n.1, p.27-32, 2010.

CAMPOS, S. Fotointerpretação da ocupação do solo e suas influências sobre a rede de drenagem da bacia do rio Capivara - Botucatu (SP), no período de 1962 a 
1977. Botucatu: UNESP, 1993. 164p. Tese (Doutorado em Energia na Agricultura) Faculdade de Ciências Agronômicas, Universidade Estadual Paulista, 1993.

CARDOSO, L.G., PIEDADE, G.C.R. Diferenciação entre unidades de solos através de agrupamentos de bacias hidrográficas. Energia na Agricultura, Botucatu, v.4, n.1, p.1726, 1989.

CHORLEY, R.J. A geomorfologia e a teoria dos sistemas gerais. Not. Geomorfol., Campinas, v.11, n.21, p.3-22, 1971.

CHRISTOFOLETTI, A. Geomorfologia. 2.ed. São Paulo: Edgard Blucher, 1974.149p.

CHRISTOFOLETTI, A. Geomorfologia. 2.ed. São Paulo: Edgard Blucher, 1980.

EMBRAPA. Centro Nacional de Pesquisa de solos. Sistema brasileiro de classificação de solos. Brasília, 1999. 412p.

FRANÇA, G.V. Interpretação fotográfica de bacias e de rede de drenagem aplicada a solos da região de Piracicaba, SP. Piracicaba, 1968,151 p., Tese (Doutoramento em solos) - Escola Superior de Agricultura "Luiz de Queiroz", Universidade de São Paulo.

HORTON, R.E. Erosional development of streams and their drainage basins:

hidrophysical approach to quantitative morphology. Bull. Geol. Soc. Am., Colorado, v.56, n.3, p.275-370, 1945.

Instituto Brasileiro de Geografia e Estatística - IBGE. Cartas do Brasil. Superintendência de Cartografia do Ministério do Planejamento e Coordenação Geral do Brasil. Folha de Lorena - SP, 1970.

Instituto Brasileiro de Geografia e Estatística - IBGE. Cartas do Brasil. Superintendência de Cartografia do Ministério do Planejamento e Coordenação Geral do Brasil. Folha de Delfim Moreira - MG, 1970.

KURKDJIAN, M.L.N.O. et al. Macrozoneamento do Vale do Paraíba e litoral norte do Estado de São Paulo. São José dos Campos: INPE, 1992, 176 p. (INPE-PRP/165).

LIMA, W. P. Princípios de hidrologia florestal para manejo de microbacias hidrográficas. Piracicaba: Escola superior de Agronomia “Luis de Queiroz", USP.1986. $318 p$.

LUEDER, D.R. Aerial photografic interpretation: principles and applications. New York: Mac Grew-Hill Book, 1959. 426 p.

MACHADO, L.M.C.P. Análise ma estruturação das redes hidrográficas e o modelo Hortoniano: uma revisão. Ver.Geogr. São Paulo, v.2, p.91-110, 1983.

MANZOLI JUNIOR, W. Unidades de solos caracterizadas por ocupação, rede de drenagem e relevo de bacias hidrográficas do município de Sud-Mennucci -SP. 
Botucatu: UNESP, 1990. 131p. Tese (Doutorado em Energia na Agricultura) - Faculdade de Ciências Agronômicas, Universidade Estadual "Júlio de Mesquita Filho", 1990.

MOREIRA, L., RODRIGUES, V.A. Análise morfométrica da microbacia da Fazenda Edgárdia - Botucatu (SP). .Eletr.Eng.Florestal. Garça, v.16, n.1, p.9-21, 2010.

MÜLLER, V.C. A quantitative geomorphology study of drainage basin characteristic in the Clinch Mountain Area. New York:Virginia and Tennesse. Dept. of Geology. n. 3, p. 30, 1953.

PIROLI, E.L. Geoprocessamento na determinação da capacidade e avaliação do uso da terra do município de Botucatu-SP. 2002. 108f. Tese (Doutorado em Agronomia/Energia na Agricultura) - Faculdade de Ciências Agronômicas, Universidade Estadual Paulista, Botucatu, 2002.

RAY, R.G. Fotografias aéreas na interpretação e mapeamento geológico. Inst.Geogr.Geol., São Paulo, 1963, 88p. (Trad. de J.F.Felicíssimo).

RODRIGUES, F.M.; PISSARRA, T.C.T.; CAMPOS, Caracterização morfométrica da microbacia hidrográfica Córrego da Fazenda Glória, Município de Taquaritinga. Irriga, Botucatu, v. 13, n.3, p. 310-322, 2008.

SCHUMM, S.A. Evolution of drainage systems and sloes in bedlands at Perth Amboy. New Jersey. Bull. Geol. Soc. Am., Colorado, v.67, p.597-646, 1956.

SILVA, A.M. et al. Combate ao uso ineficiente da água no município de Piquete - SP. I Seminário Difusão Tecnológica em Recursos Hídricos, FCTH/CEIVAP, Volta Redonda, 1-15, 12 e 13 Nov. 2002.

SILVA, A.M. Caracterização agroambiental de área de mananciais do Rio Paraíba do Sul, Piquete (SP), utilizando técnicas de geoprocessamento e fotointerpretação. 84f. Dissertação (Mestrado em Agronomia/Energia na Agricultura) - Faculdade de Ciências Agronômicas, Universidade Estadual Paulista, Botucatu, 2003.

SMITH, K.G. Standards for grading texture of erosional topography. American Journal of Science, New Haven, v.248, p.655-668, 1950.

STRALHER, A. N.. Quantitative analysis of watershed geomorphology. Trans. Am. Geophys. Un., New Haven, v.38, p.913-20, 1957.

STRALHER, A. N.. Dimensional analysis applied to fluvially eroded landforms. Bull. Geol. Soc. Am., Colorado, v.69, p.279-300, 1958.

TORRES, J.L.R. et al. Diagnóstico ambiental e análise morfométrica da microbacia do Córrego Lanhoso em Uberaba - MG. Caminhos da Geografia, Uberlândia, v.9, n.5, p.111, 2007. 
VIEIRA, T.G.C. 1991. Fotointerpretação de atributos de drenagem e relevo na diferenciação de solos do município de Lavras, MG. (Dissertação de Mestrado), Escola Superior de Agricultura de Lavras. 135 p. 